\title{
Non-surgical Treatment of Condylar Fracture in an 11-Year-Old Patient: a Case Report
}

\author{
Angela Pia Cazzolla', Graziano Montaruli², Nunzio Francesco Testa ${ }^{2}$, Gianfranco Favia ${ }^{1}$, Maria \\ Grazia Lacaita $^{1}$, Lorenzo Lo Muzio ${ }^{2}$, Domenico Ciavarella ${ }^{2}$ \\ ${ }^{1}$ Department of Surgical Sciences, Faculty of Medicine, School of Dentistry, University of Bari, Bari, Italy. \\ ${ }^{2}$ Department of Clinical and Experimental Medicine, Faculty of Medicine, School of Dentistry, University of Foggia, Foggia, \\ Italy.
}

\author{
Corresponding Author: \\ Graziano Montaruli \\ Via Rovelli 50, 71122, Foggia \\ Italy \\ Phone: +390881588080 \\ Fax: +390881 588081 \\ E-mail: graziano.montaruli@unifg.it
}

\begin{abstract}
Background: Mandibular condylar fractures commonly occur after trauma and account for 25 to $35 \%$ of all mandibular fractures; its appropriate therapy still remains a point of controversy in children. The purpose of this paper is to describe the treatment of an 11-years-old male patient affected by neck-condylar fracture as result of trauma in evolutive age.

Methods: No surgical treatment was performed. A functional therapy was applied with a jaw splint. A closed treatment for mandibular condyle fractures was preferred because the amount of condylar displacement wasn't considerable.

Results: The early treatment with functional therapy generated a functional adaptation of the condyle in the glenoid fossa and a normal mandibular function. After a 12-month follow-up the fracture resolution and an optimal condylar position were recorded.

Conclusions: The current case report and literature review showed that non-surgical therapy of neck-condylar fracture in a child with lower resin splint can restore mandibular movements and aesthetics. Facial growth after one year treatment resulted normal. A conservative treatment may be appropriate for children in selected cases with minimally displaced condyle.
\end{abstract}

Keywords: jaw fractures; mandibular fractures; traumatic dental occlusion.

\author{
Accepted for publication: 18 June 2018 \\ To cite this article: \\ Cazzolla AP, Montaruli G, Testa NF, Favia G, Lacaita MG, Lo Muzio L, Ciavarella D. \\ Non-surgical Treatment of Condylar Fracture in an 11-Year-Old Patient: a Case Report \\ J Oral Maxillofac Res 2018;9(2):e5 \\ URL: http://www.ejomr.org/JOMR/archives/2018/2/e5/v9n2e5.pdf \\ doi: $10.5037 /$ jomr.2018.9205
}




\section{INTRODUCTION}

Mandibular condylar fractures commonly occur after trauma and account for 25 to $35 \%$ of all mandibular fractures [1]. Two forms are described: intra-capsular and extracapsular [2]. Intra-capsular fractures of the mandibular condyle interest the condylar head and may involve its medial pole (Type 1), or the lateral condylar pole with loss of vertical height of the mandibular ramus (Type 2), or multiple fragments (Type 3). The findings of international literature report more cases of extracapsular fractures compared to intracapsular fractures [3] .

Sagittal or vertical fractures of the mandibular condyle and chip fractures of the medial part of the condylar head are uncommon [4]. The main treatments for condyle fractures are: 1) a period of maxillomandibular advancement followed by functional therapy; 2) surgical reduction with or without internal fixation [5]. The choice of treatment is a debated issue in oral and maxillofacial traumatology especially regarding surgical (open) and non-surgical (closed) treatment [6]. Many authors suggest that surgical treatment is advocated for adults with condylar fractures while in children condylar fractures often resolve with closed treatment (Figure 1). Clinically the patients present pain, limitation of motion (maximum mouth opening, left and right mandibular moving, eating food), difficulty in speaking, resting, smiling and mandibular midline deviation toward the affected side.

The diagnosis of condylar neck fracture is done by means of clinical and radiographic evaluation. The most used radiographs in the diagnosis of condylar fractures are the panoramic radiography, the cranium lateral teleradiography, the cranium frontal teleradiography and cone-beam computed tomography $[\underline{7}, \underline{8}]$.

In this paper the treatment of a growing patient with a neck-condylar fracture as a result of trauma is described.

\section{CASE DESCRIPTION AND RESULTS}

An 11-year-old male Italian Caucasian patient was urgently visited for trauma occurred during leisuretime activity in the Division of Pediatric Dentistry, Department of Surgical Sciences, University of Bari. In extraoral evaluation a laceration localized to soft tissues of the chin associated to a minimum mandibular movement restriction and a mandibular midline deviation toward the affected side were evidenced (Figures 2A, 2B). The patient reported pain around the auricular zone and pain at the palpation of

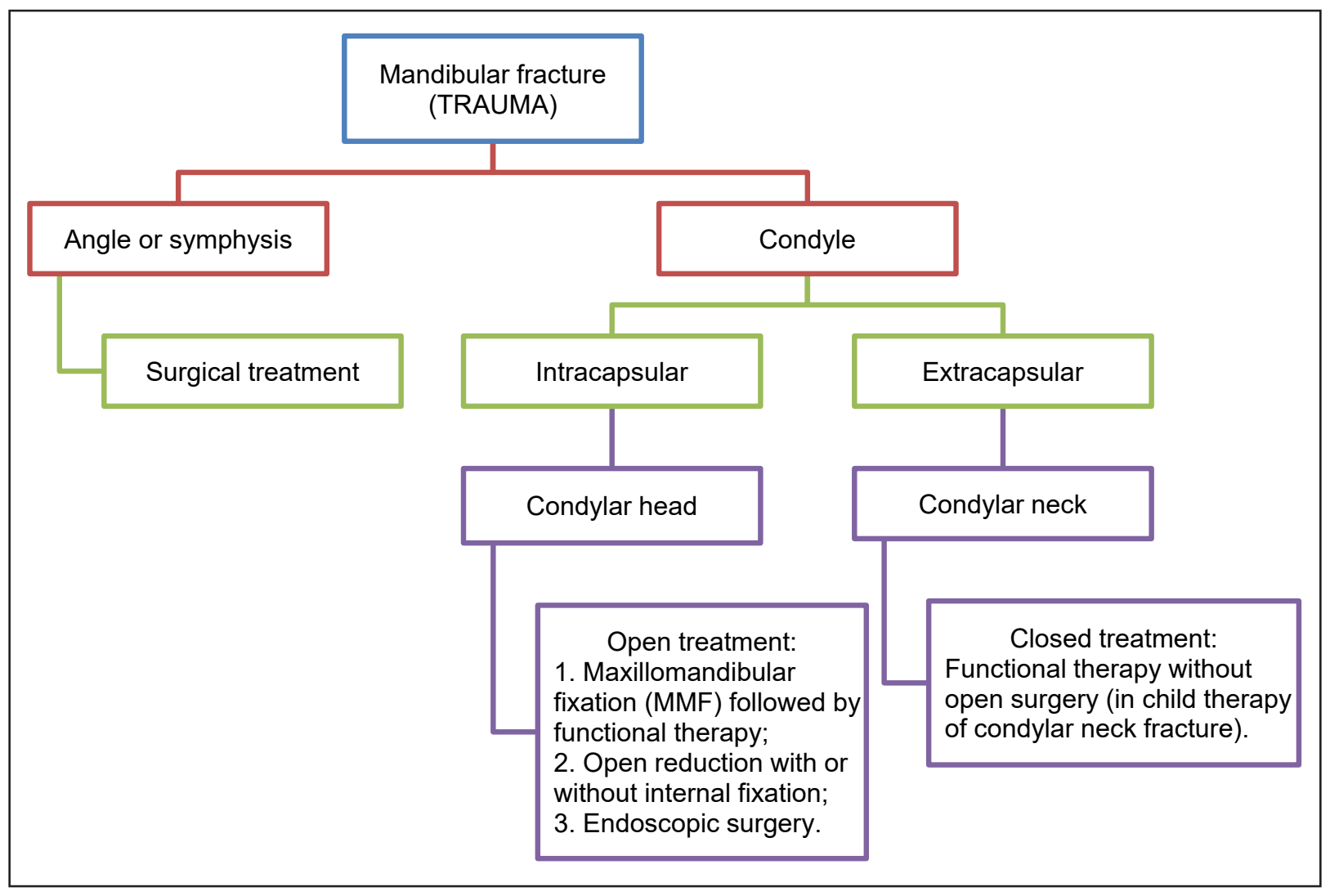

Figure 1. Mandibular fracture localization and treatment. 


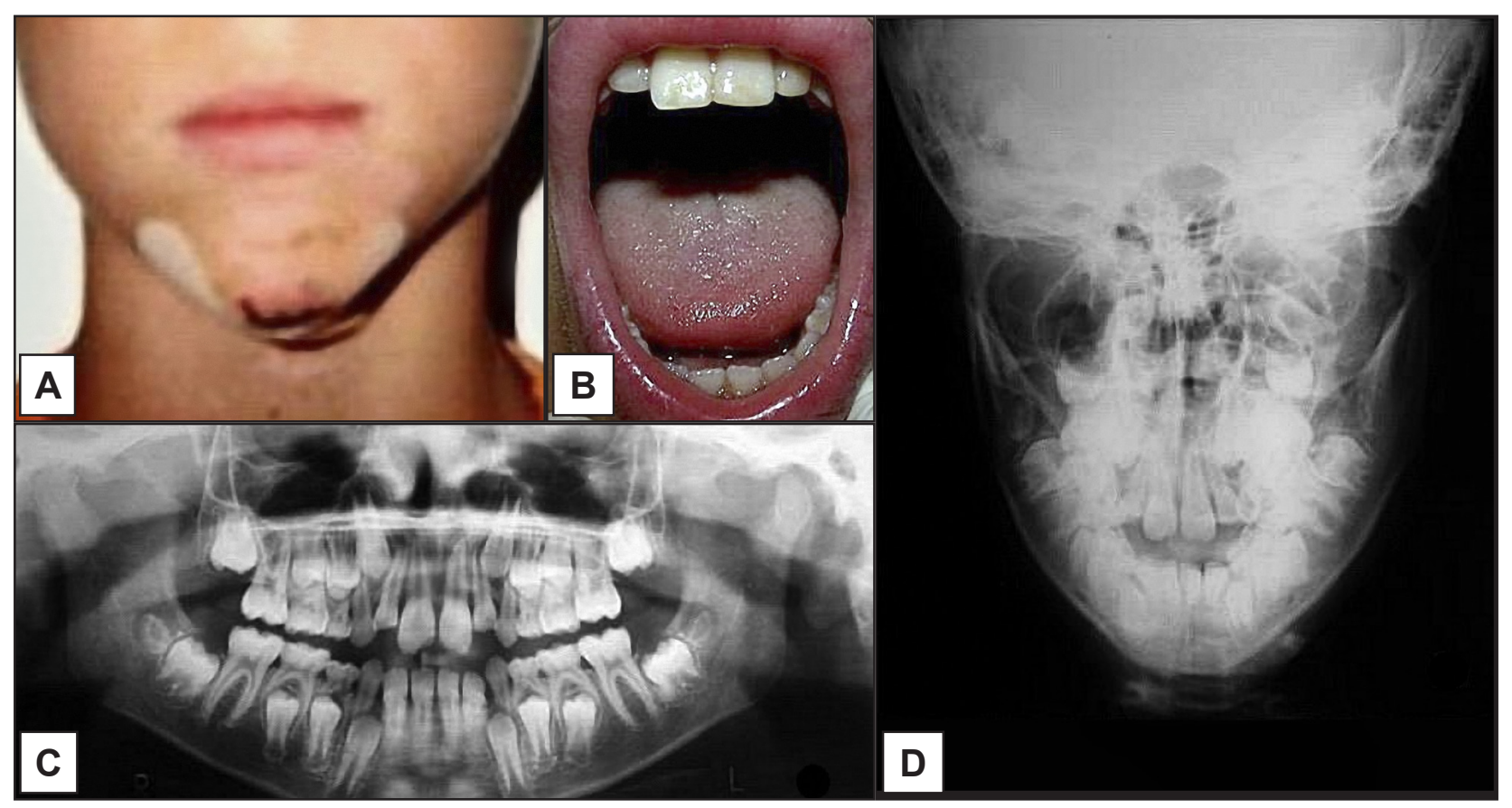

Figure 2. $\mathrm{A}=$ Frontal image of the mandible at the time of the trauma.

$\mathrm{B}=$ Intraoral photograph of the patient showing lateral deviation toward the affected side.

$\mathrm{C}=$ Panoramic radiograph showing condylar fracture and incisors lesion.

$\mathrm{D}=$ Pre-treatment frontal radiograph underlined the deviation of the mandible on the left side.

left masseter and lateral pterygoid muscles. In intraoral evaluation the dislocation of the maxillary central incisors (i.e. 1.1/2.1) was evidenced. On the same teeth a fracture of the enamel and dentin occurred. Vitality cold test performed with ethyl chloride resulted positive. Deviation of the lower incisal midline occurred to the left; Class I occlusion on the right while Class II occlusion on the left side were observed.

The panoramic radiography and a frontal teleradiography were performed. A left condylar neck fracture and posterior displacement of condyle were highlighted on these radiographs (Figures 2C, 2D).

Enamel and dentin fractures on teeth 1.1 and 2.1 were restored by composite resin.

Due to the patient's young age the functional (closed) treatment for the condyle fracture was chosen, an intermaxillary splint allowing an early mandibular function and masticatory muscles exercises were performed.

Maxillary and mandibular impressions were performed using irreversible hydrocolloid material (Orthoprint-Zhermack ${ }^{\circledR}$, Badia Polesine, Italy) in unperforated impression trays in order to reproduce physiologic condylar position. Casts were quickly obtained using type IV high-strength dental plaster (FujiRock $\mathrm{EP}^{\circledR}$ [GC America Inc., Alsip, Illinois, USA], Vel-Mix ${ }^{\mathrm{TM}}$ [Kerr Corp., Orange, California, USA], Suprastone ${ }^{\circledR}$ [Kerr Corp., Orange, California, USA]) and mounted on the articulator (Panadent
Corp., Grand Terrace, Calif, California, USA) according to the manufacturer's instructions.

The maxillary cast was mounted using the facial transfer bow in order to locate the estimated hinge axis. The face-bow was oriented paralleling to the Frankfurt horizontal plane. The wax bite was taken with Delar Bite Registration Wax (Delar Corp, Lake Oswego, Oregon, USA) and made in two sections. The anterior section was made by folding the softened wax over in order to form three or more layers including the upper and lower anterior teeth. The posterior section was two layers thick. The anteroposterior dimension was conformed to include the first and second molars. During anterior wax recording the patient was tilted at 45 degree angle to the floor. Waxes were softened in water at 75 degrees Celsius and then placed on the maxillary anterior teeth.

The patient was instructed to close the mandible far back posteriorly until a space of $2 \mathrm{~mm}$ could be seen between the first posterior teeth contact. For posterior recording the softened wax was placed on the upper teeth together with the anterior wax just recorded. In this way the anterior wax acted as a "guide-stop" for physiologic condylar centric relation (CR) recording. The wax was then taken and given to the dental technician for the construction of a lower splint.

The splint was built in acrylic resin with definite contacts (upper supporting cusps) (Figure 3). The bite was built oriented parallel to the true horizontal plane 


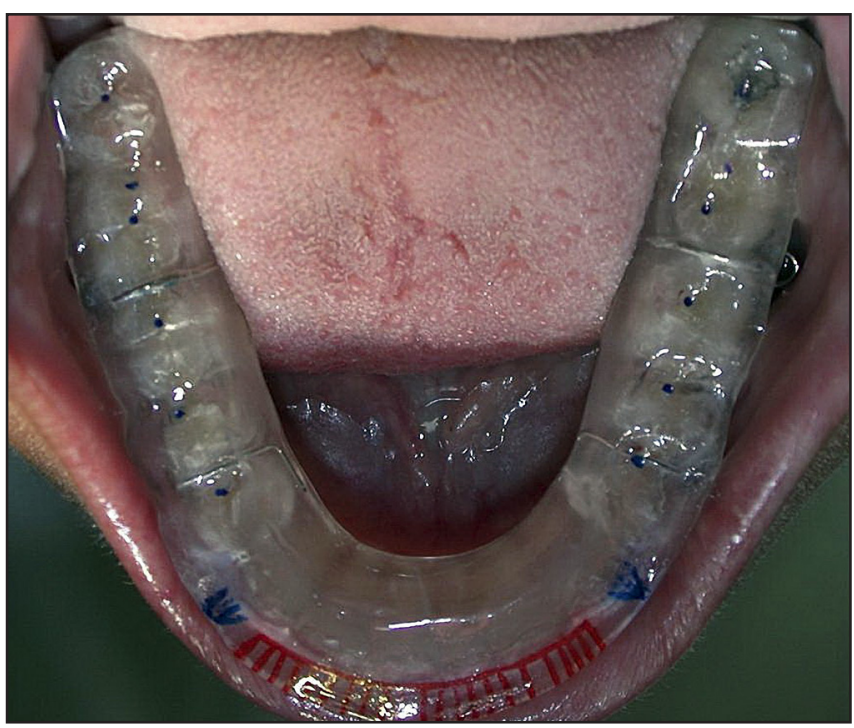

Figure 3. The jaw splint with definite contacts (upper supporting cusps) and lateral/protrusive guides. in order to obtain the stretching of the left fractured condyle. Resin thickness of the left side of the splint was higher than the right side.

Mouth opening exercises and muscles stretch were performed several times a day by the patient while the splint was used $24 \mathrm{~h}$ per day and during meals. Every 15 days the patient underwent a visit and a bite check. On the left side small amount of resin was positioned to improve condylar vertical growth. After a 12-month follow-up the fracture's resolution and an optimal condylar position were recorded. Mandibular midline alignment and good mandible function, bilateral Class I molar relationship (i.e. normal intermaxillary dental relationships), good symmetry of dental arches, no pain on trigger points during manual palpation were detected (Figures 4A, 4B). An orthopantomogram and a frontal teleradiography were performed (Figures 4C, 4D).

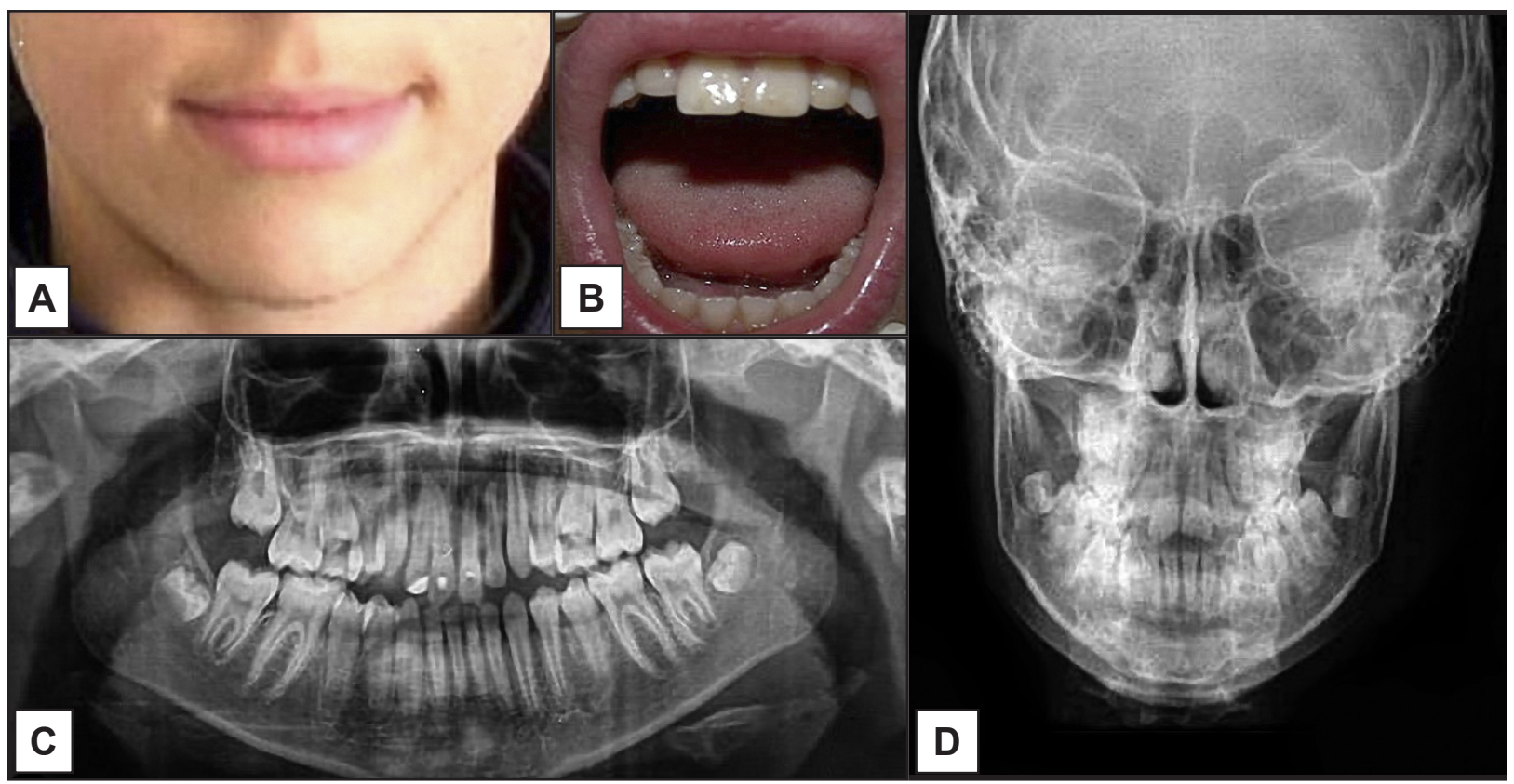

Figure 4. A = Post-treatment frontal image of the mandible.

$\mathrm{B}=$ Intraoral photograph of the patient showing no deviation in opening mouth.

$\mathrm{C}=$ Post-treatment panoramic radiograph showing condylar fracture resolution.

$\mathrm{D}=$ Post-treatment frontal radiograph showing condylar fracture resolution.

\section{DISCUSSION}

Meikle [9] and Copray et al. [10] showed that condylar cartilage was not a centre of growth (i.e. genetically programmed) but a secondary cartilage influenced by many factors such as functional matrices [11]. The most serious complication of condylar fractures is temporomandibular joint (TMJ) ankylosis $[\underline{12}, \underline{13}]$ that develops particularly after an intra-articular trauma with cartilage or disc lesion or after post-traumatic intra-articular inflammation [14]. Other complications such as functional constraints to articular movements, midline deviation and the consolidation of fragments in the dislocated position may be possible $[\underline{15}, \underline{16}]$. In addition, some authors showed that an unbalanced masticatory function may induce a different condylar growth in young people [17].

An appropriate therapy in child mandibular condyle fracture still remains a point of controversy. Some authors suggest open reduction [18, 19] or short term intermaxillary fixation [20]. 
In the last years open approach had great interest for introduction of non invasive surgical technique such as endoscopic surgery [21]. Many significant long-term results with this noninvasive technique have been there. The absolute indications for open treatment of condylar fracture are in bilateral fractures [22-24], in considerable dislocations [6,25-27] when closed treatment isn't able to re-establish occlusion $[\underline{28}, \underline{29}]$ and when concomitant fractures of other areas of the face occurred.

Nevertheless literature's analysis showed that child fracture resolution with close treatment is preferred [4]. In fact Gilhuus-Moe [30], Lund [31] and Minervini et al. [32] demonstrated that the closed therapy for condylar fractures in children may regenerate condylar structure with function and growth recovery. However child's age, adequacy of function of the mandible, degree of displacement or dislocation of the condylar fragment and need for active kinesiotherapy should be considered in all cases $[32,33]$.

Within the limits of this case report we showed that in growing patients the restoring of mandibular movements is enough to obtain normal facial growth and prevent the development of facial asymmetry when unilateral fracture occurs.

\section{CONCLUSIONS}

The current case report focuses on non-surgical therapy of neck-condylar fracture in a child with lower resin splint and its resolution and stability after one year treatment.

Although we should consider this case report as a limited study, we must emphasize the effectiveness of a non-invasive treatment that doesn't require surgery.

The use of an easily manageable occlusal splint offer an excellent chance of regeneration and continued normal development after fracture in growing patients. The remodelling process of the condylar head and neck is observed in the panoramic radiographs and in postero-anterior radiography.

The present paper indicates that conservative treatment may be appropriate for children in selected cases with minimally displaced condyle in order to obtain restoration of mandibular function and aesthetics.

\section{ACKNOWLEDGMENTS AND DISCLOSURE STATEMENTS}

The authors report no conflicts of interest related to this study.

\section{REFERENCES}

1. Ellis E, Throckmorton GS. Treatment of mandibular condylar process fractures: biological considerations. J Oral Maxillofac Surg. 2005;63(1):115-34. [Medline: 15635566] [doi: 10.1016/j.joms.2004.02.019]

2. Mitchell DA. A multicentre audit of unilateral fractures of the mandibular condyle. Br J Oral Maxillofac Surg. 1997;35(4):230-6. [Medline: 9291258] [doi: 10.1016/S0266-4356(97)90038-3]

3. Zachariades N, Mezitis M, Mourouzis C, Papadakis D, Spanou A. Fractures of the mandibular condyle: a review of 466 cases. Literature review, reflections on treatment and proposals. J Craniomaxillofac Surg. 2006;34(7):421-32. [Medline: 17055280] [doi: $10.1016 / j . j \mathrm{jcms} .2006 .07 .854]$

4. Valiati R, Ibrahim D, Abreu ME, Heitz C, de Oliveira RB, Pagnoncelli RM, Silva DN. The treatment of condylar fractures: to open or not to open? A critical review of this controversy. Int J Med Sci. 2008;5(6):313-8. [Medline: 18974859] [doi: 10.7150/ijms.5.313]

5. Ellis E, 3rd. Condylar process fractures of the mandible. Facial Plast Surg. 2000;16(2):193-205. [Medline: 11802368] [doi: $10.1055 / \mathrm{s}-2000-12579$ ]

6. Villarreal PM, Monje F, Junquera LM, Mateo J, Morillo AJ, Gonzalez C. Mandibular condyle fractures: determinants of treatment and outcome. J Oral Maxillofac Surg. 2004;62(2):155-63. [Medline: 14762747] [doi: 10.1016/j.joms.2003.08.010]

7. Poveda Roda R, Diaz Fernandez JM, Hernandez Bazan S, Jimenez Soriano Y, Margaix M, Sarrion G. A review of temporomandibular joint disease (TMJD). Part II: Clinical and radiological semiology. Morbidity processes. Med Oral Patol Oral Cir Bucal. 2008;13(2):E102-9. [Medline: 18223525]

8. Farronato G, Grillo ME, Giannini L, Farronato D, Maspero C. Long-term results of early condylar fracture correction: case report. Dent Traumatol. 2009;25(3):e37-42. [Medline: 19239483] [doi: 10.1111/j.1600-9657.2008.00750.x]

9. Meikle MC. The role of the condyle in the postnatal growth of the mandible. Am J Orthod. 1973;64(1):50-62. [Medline: 4577167] [doi: 10.1016/0002-9416(73)90280-7]

10. Copray JC, Jansen HW, Duterloo HS. Growth of the mandibular condylar cartilage of the rat in serum-free organ culture. Arch Oral Biol. 1983;28(10):967-74. [Medline: 6580855] [doi: 10.1016/0003-9969(83)90095-X] 
11. Moss ML, Rankow RM. The role of the functional matrix in mandibular growth. Angle Orthod. 1968;38(2):95-103. [Medline: 5239131]

12. Vuillemin T, Ladrach K, Raveh J. [Indications for surgical management of condylar fractures]. HNO. 1988;36(11): 467-71. [Medline: 3069818]

13. Eulert S, Proff P, Bokan I, Blens T, Gedrange T, Reuther J, Bill J. Study on treatment of condylar process fractures of the mandible. Ann Anat. 2007;189(4):377-83. [Medline: 17695996] [doi: 10.1016/j.aanat.2007.02.010]

14. Raveh J, Vuillemin T, Ladrach K, Sutter F. Temporomandibular joint ankylosis: surgical treatment and long-term results. J Oral Maxillofac Surg. 1989;47(9):900-6. [Medline: 2547919] [doi: 10.1016/0278-2391(89)90371-6]

15. Assael LA. Open versus closed reduction of adult mandibular condyle fractures: an alternative interpretation of the evidence. J Oral Maxillofac Surg. 2003;61(11):1333-9. [Medline: 14613091] [doi: 10.1016/S0278-2391(03)00736-5]

16. Eckelt U, Schneider M, Erasmus F, Gerlach KL, Kuhlisch E, Loukota R, Rasse M, Schubert J, Terheyden H. Open versus closed treatment of fractures of the mandibular condylar process-a prospective randomized multi-centre study. J Craniomaxillofac Surg. 2006 Jul;34(5):306-14. [Medline: 16781159] [doi: 10.1016/j.jcms.2006.03.003]

17. Ciavarella D, Mastrovincenzo M, Sabatucci A, Campisi G, Di Cosola M, Suriano M, Lo Muzio L. [Primary and secondary prevention procedures of temporo-mandibular joint disease in the evolutive age]. Minerva Pediatr. 2009 Feb;61(1):93-7. Italian. [Medline: 19180004]

18. Khosla VM, Boren W. Mandibular fractures in children and their management. J Oral Surg. 1971;29:116-21. [Medline: 5279096]

19. James RB, Fredricson C, Kent JN. Prospective study of mandibular fractures. J Oral Surg. 1981;39:275-81. [Medline: 6937624]

20. Guven O, Keskin A. Remodelling following condylar fractures in children. J Craniomaxillofac Surg. 2001;29(4):232-7. [Medline: 11562093] [doi: 10.1054/jcms.2001.0228]

21. Zimmermann CE, Troulis MJ, Kaban LB. Pediatric facial fractures: recent advances in prevention, diagnosis and management. Int J Oral Maxillofac Surg. 2005;34:823-33. [Medline: 16154722] [doi: 10.1016/j.ijom.2005.06.015]

22. Terai H, Shimahara M. Closed treatment of condylar fractures by intermaxillary fixation with thermoforming plates. Br J Oral Maxillofac Surg. 2004;42(1):61-3. [Medline: 14706305] [doi: 10.1016/S0266-4356(03)00205-5]

23. Banks P. A pragmatic approach to the management of condylar fractures. Int J Oral Maxillofac Surg. 1998;27(4):244-6. [Medline: 9698168 ] [doi: 10.1016/S0901-5027(05)80504-1]

24. Hirota Y, Habu M, Tominaga K, Sukedai M, Matsukawa A, Nishihara T, Fukuda J. Relationship between TNF-alpha and TUNEL-positive chondrocytes in antigen-induced arthritis of the rabbit temporomandibular joint. J Oral Pathol Med. 2006 Feb;35(2):91-8. [Medline: 16430739] [doi: 10.1111/j.1600-0714.2006.00367.x]

25. De Riu G, Gamba U, Anghinoni M, Sesenna E. A comparison of open and closed treatment of condylar fractures: a change in philosophy. Int J Oral Maxillofac Surg. 2001;30(5):384-9. [Medline: 11720039] [doi: 10.1054/ijom.2001.0103]

26. Raab GE, Davis CM, 3rd. Early healing with locked condylar plating of periprosthetic fractures around the knee. J Arthroplasty. 2005;20(8):984-9. [Medline: 16376252] [doi: 10.1016/j.arth.2005.03.040]

27. Santler G, Karcher H, Ruda C, Kole E. Fractures of the condylar process: surgical versus nonsurgical treatment. J Oral Maxillofac Surg. 1999;57(4):392-7; discussion 7-8. [Medline: 10199490] [doi: 10.1016/S0278-2391(99)90276-8]

28. Haug RH, Assael LA. Outcomes of open versus closed treatment of mandibular subcondylar fractures. J Oral Maxillofac Surg. 2001;59(4):370-5; discussion 5-6. [Medline: 11289165] [doi: 10.1053/joms.2001.21868]

29. Brandt MT, Haug RH. Open versus closed reduction of adult mandibular condyle fractures: a review of the literature regarding the evolution of current thoughts on management. J Oral Maxillofac Surg. 2003;61(11):1324-32. [Medline: 14613090] [doi: 10.1016/S0278-2391(03)00735-3]

30. Gilhuus-Moe O. Fractures of the mandibular condyle: a clinical and radiographic examination of 62 patients injured in the growth period. Trans Int Conf Oral Surg. 1970:121-30. [Medline: 5282453]

31. Lund K. Mandibular growth and remodelling processes after condylar fracture. A longitudinal roentgencephalometric study. Acta Odontol Scand Suppl. 1974;32(64):3-117. [Medline: 4534309]

32. Minervini G, Lucchese A, Perillo L, Serpico R. Unilateral superior condylar neck fracture with dislocation in a child treated with an acrylic splint in the upper arch for functional repositioning of the mandible. Cranio. 2016:1-5. [Medline: 27398739] [doi: 10.1080/08869634.2016.1203560]

33. Theologie-Lygidakis N, Chatzidimitriou K, Tzerbos F, Gouzioti A, Iatrou I. Nonsurgical management of condylar fractures in children: A 15-year clinical retrospective study. J Craniomaxillofac Surg. 2016;44(2):85-93. [Medline: 26740368] [doi: 10.1016/j.jcms.2015.11.011] 


\section{To cite this article:}

Cazzolla AP, Montaruli G, Testa NF, Favia G, Lacaita MG, Lo Muzio L, Ciavarella D.

Non-surgical Treatment of Condylar Fracture in an 11-Year-Old Patient: a Case Report

J Oral Maxillofac Res 2018;9(2):e5

URL: http://www.ejomr.org/JOMR/archives/2018/2/e5/v9n2e5.pdf

doi: $\underline{10.5037 / \text { jomr.2018.9205 }}$

Copyright (C) Cazzolla AP, Montaruli G, Testa NF, Favia G, Lacaita MG, Lo Muzio L, Ciavarella D. Published in the JOURNAL OF ORAL \& MAXILLOFACIAL RESEARCH (http://www.ejomr.org), 29 June 2018.

This is an open-access article, first published in the JOURNAL OF ORAL \& MAXILLOFACIAL RESEARCH, distributed under the terms of the Creative Commons Attribution-Noncommercial-No Derivative Works 3.0 Unported License, which permits unrestricted non-commercial use, distribution, and reproduction in any medium, provided the original work and is properly cited. The copyright, license information and link to the original publication on (http://www.ejomr.org) must be included. 